\section{DIGITAL COMMONS \\ @ UNIVERSITY OF SOUTH FLORIDA}

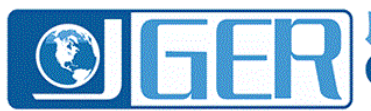

Journal of

Global Education and Research

June 2018

\title{
Ensuring academic success of student-athletes: Research on the relationship of academic measures of success and graduation rates
}

Jessica Chrabaszcz

Yale University, jessica.chrabaszcz@yale.edu

Leslie Cordie

Auburn University, lak0007@auburn.edu

Michael Wooten

Auburn University, wootemc@auburn.edu

Follow this and additional works at: https://digitalcommons.usf.edu/jger

Part of the Adult and Continuing Education Commons

This Refereed Article is brought to you for free and open access by the M3 Center at the

University of South Florida Sarasota-Manatee at Digital Commons @ University of South Florida. It has been accepted for inclusion in Journal of Global Education and Research by an authorized editor of Digital Commons @ University of South Florida. For more information, please contact digitalcommons@usf.edu.

\section{Recommended Citation}

Chrabaszcz, J., Cordie, L., \& Wooten, M. (2018). Ensuring academic success of student-athletes: Research on the relationship of academic measures of success and graduation rates. Journal of Global Education and Research, 2(1), 1-16. https://www.doi.org/10.5038/2577-509X.2.1.1013

Corresponding Author

Jessica Chrabaszcz, Yale University

Revisions

Submission date: Oct. 3, 2017; 1st Revision: Jan. 19, 2018; Acceptance: Jun. 8, 2018 


\title{
Ensuring Academic Success of Student- Athletes: Research on the Relationship of Academic Measures of Success and Graduation Rates
}

\author{
Jessica Chrabaszcz ${ }^{1}$, Leslie Cordie ${ }^{2}$, and Michael Wooten ${ }^{3}$
}

\author{
Varsity Sport Administration \\ Yale University, United States \\ 1 jessica.chrabaszcz@yale.edu \\ College of Education \\ Auburn University, United States \\ ${ }^{2}$ lesliecordie@auburn.edu \\ College of Sciences and Mathematics \\ Auburn University, United States \\ ${ }^{3}$ wootemc@auburn.edu
}

\begin{abstract}
The National Collegiate Athletic Association (NCAA) has implemented metrics to track the academic success of student-athletes in higher education. This study was designed to evaluate the relationship between three metrics used by the NCAA as part of it monitoring and compliance program for academic achievement by student-athletics. Our study examined the relationships between Academic Progress Rate (APR), Graduation Success Rate (GSR), and Federal Graduation Rate (FGR). The data set consisted of 720 total APR, GSR, and FGR scores for the years 20032006 obtained from 14 Southeastern Conference (SEC) programs. A subset of six sports with samples sizes of 20 or larger were analyzed in detail. Distributions for FGR, GSR, and APR exhibited substantial differences. Overall, the broadest distribution was observed among FGR estimates. GSR scores were positively related to FGRs. However, both GSR and APR scores were skewed toward high levels of success suggesting that they exhibit limited predictive power. Overall, our results indicated that additional research is needed to optimize both the GSR and APR metrics so they can more precisely serve as indicators of academic progress.
\end{abstract}

Keywords: higher education, academic progress metrics, NCAA, compliance

\section{Introduction}

Ensuring academic success of student-athletes is a critical yet highly complex undertaking. Educational institutions invest substantial resources into strategies to increase academic success by student-athletes. Incentive for such investment results from both the educational commitment made by all universities to their students, be they athletes or not, and by mandates set forth by governing bodies such as the National Collegiate Athletic Association (NCAA). Over the past two decades, attempts to ensure viable academic opportunities for student-athletes have been at the 
Journal of Global Education and Research, Vol. 2, Iss. 1 [2018], Art. 1, pp. 1- 16

forefront of NCAA policy making: for examples, 1.6 Rule, Proposition 48, Proposition 16 (Waller, 2003). Comeaux (2011) highlighted this effort in stating that:

Over the past decade, the National College Athletic Association (NCAA) Division I Board of Directors has intensified its efforts to improve the educational experiences of studentathletes and to bring some sense of balance between athletics and the university's traditional educational roll. (p. 521)

In 1990, these activities led to a landmark decision by the NCAA to require the collection and reporting of graduation rates for participants in athletic programs (Petr \& Paskus, 2009). Since this ruling, the NCAA has continued to emphasize the importance of producing success in classrooms that mirrors success on the playing fields. Unfortunately, as with any set of standards, reporting requirements instituted by the NCAA have sometimes been problematic and controversial (Le Crom, Warren, Clark, Marolla, \& Gerber, 2009; Kirkpartrick, Hawkins, Hill, \& Maxcy, 2014). In addition, the potential for severe penalties to programs that fail to meet minimum standards places immense pressure on athletic departments and in turn their student-athletes. Because of the widespread impact that NCAA sanctions can have, it is essential that the metrics used to evaluate a program's success are accurate and precise.

\section{Academic Success Metrics}

A plethora of methods have been proposed to address the complex problem of quantifying student success in the educational environment. To measure the academic performance of student-athletes, three metrics have played key roles. The Federal Graduation Rate (FGR) was the first measure applied to higher education institutions and all students on academic progress. However, this metric did not take into account certain circumstances that only pertain to student-athletes. In response, the NCAA developed two alternate metrics that were intended to be more consistent with the conditions confronting student-athletes. The athlete-specific metrics created by the NCAA are the Graduation Success Rate (GSR) and the Academic Progress Rate (APR) (Academic Progress Rates, n.d.; Graduation Rates, n.d.).

\section{The Federal Graduation Rate}

The Federal Graduation Rate (FGR) is a statistic compiled by the U.S. Department of Education and is used as an indicator of academic success for all college students (Academic Progress Rates, n.d.). The FGR measures the percentage of first-time, full-time freshmen who graduate within six years of entering their original four-year institution. Collection of FGR data by the NCAA began in 1984 (Petr \& Paskus, 2009). Starting in 1990, the NCAA was required through the Department of Education Student Right-to-Know Act to release these data (Horn, 2010). This law required universities receiving federal funds to report FRG for all students, and more specifically to report separately the FRG for student-athletes. In National Center for Education Research report by Chen, Bersudskaya, and Cubarrubi (2011), they state that:

In addition, it requires postsecondary institutions that receive Title IV funds to submit an annual report to the Department of Education containing information on enrollment and graduation rates disaggregated by gender, race/ethnicity, receipt of athletic scholarships, and by type of sport. (p. 3) 
The law also required universities to provide additional information to the federal government. This information includes, but is not limited to, cost of attendance, accreditation and academic program data, security reports, and financial aid (Southall, 2012).

There has been substantial criticism of FGR relating to the fact that this metric does not take into account numerous situations that are specific to student-athletes. The FGR is not adjusted, for example, for student-athletes who transfer in or out of a specific institution regardless of whether or not they finish their degree elsewhere and are academically eligible. It also does not factor in students who change their enrollment status from full-time to part-time after they are initially counted in a cohort (Southall, 2012). Another limitation of the FGR includes how data from walkons, who can make up close to $50 \%$ of all athletes within an institution, are included in FGR calculations. The size of the athletic population for any one cohort can also be an issue in FGR (Ferris, Finster, \& McDonald, 2004). Due to the small sample size within a conference, institution, or team, usually a 10-year population is examined within college athletics. However, small population sizes can cause a large swing in FGR from year to year, making its usefulness limited. Quite importantly, the FGR also fails to acknowledge differences in academic rigor across majors and institutions. Lastly, FGR only looks at individuals who remain at and graduate from the same institution within six years after enrolling. Any student who transfers from the institution or takes longer than six years to complete a degree is counted against the institution regardless of whether they were eligible upon transferring or graduated after the six year timeframe (Ferris, Finster, \& McDonald, 2004). Due to these, and other, issues, the NCAA no longer recognizes FGR as a determinant factor for academic progress of athletic teams. As a result, the NCAA has developed their own metrics to hold their athletic programs, coaches, and administrators accountable for student-athletes.

\section{Graduation Success Rate}

The Graduation Success Rate (GSR) is a measure developed by the NCAA in 1995 to determine academic success for student-athletes separate from FGR (Graduation Rates, n.d.). This rate is unique for student-athletes since it only applies to those student-athletes who receive athletics aid (LaForge \& Hodge, 2011). The rate differs from FGR because it does not penalize student-athletes who transfer and are academically eligible, and it credits the institution for midyear transfers who enroll and graduate (Sander, 2009). In 2009, Sander noted:

The NCAA uses its own formula to calculate the GSR of Division I athletes. The figures are different from the graduation rate calculated by the U.S. Department of Education. The NCAA statistics, unlike the federal ones, do not penalize institutions when athletes transfer to other colleges as long as they depart in good academic standing. (para. 8)

Each university and athletic program is responsible for reporting their GSR to the NCAA, which in turn determines if the program is eligible for competition. GSR is completed and accounted for on a sport-by-sport basis, thus making GSR useful in accessing the academic performance of individual teams within an institution. As LaForge and Hodge (2011) observed, "GSR removes early departures in good academic standing from the cohort. There is, therefore, little ambiguity surrounding the interpretation of a low GSR" (p. 226). Intra-campus comparisons of GSR between sports is considered valid and useful because it reflects the same academic rigors among teams, 
Journal of Global Education and Research, Vol. 2, Iss. 1 [2018], Art. 1, pp. 1- 16

and it removes the effects of differing professional opportunities from sport to sport (LaForge \& Hodge, 2011).

\section{Academic Progress Rate}

Though the NCAA continues to use GSR to measure academic success of student-athletes, the NCAA has also developed another metric in the past several years. This metric, the Academic Progress Rate (APR), integrates data on the eligibility and retention of each student-athlete across academic terms (Academic Progress Rate, n.d.). This metric is being used with the GSR to develop standards that universities and athletic programs are required to meet in order to participate in postseason play and to remain eligible within the NCAA.

The Academic Progress Rate (APR) metric was established during the 2003-2004 academic year as a response when athletics programs recognized a need to track student-athletes throughout their college careers (Christy, Seifried, \& Pastroe, 2008). The Academic Progress Rate measures the academic achievement of Division I teams during each academic term. Each student-athlete earns one point for staying in school and one point for being academically eligible. A team's total points are divided by points possible and multiplied by 1,000 to produce the team's APR (Division I Academic Progress Rate, 2011). A school's APR is reported to the NCAA each year from which a four year, multi-year APR Rate is generated (NCAA Division I Manual, 2012-2013). Since the APR is a snapshot of each athlete, on each specific team, within each academic semester, it provides the athletic department, administrators, and coaches with a progress indicator of how each athlete is completing progress towards degree requirements and moving towards graduation (Division I Academic Progress Rate, 2011). Therefore, if an athlete falls off track with their academic progress, APR allows the team and institution time to help the athlete continue to progress towards the ultimate goal of graduation. In addition, APR is a real time statistic in that it is computed each academic semester. This aspect makes the metric especially useful because it can be used for intra-institutional comparisons of teams because each sport functions under the same academic factors present at a given institution (LaForge \& Hodge, 2011).

Each Division I team is required to calculate its APR each academic year. Based on eligibility, graduation, and retention of each scholarship student-athlete, within each team, this number has a maximum of 1,000. Teams that score below certain thresholds (currently 930) can face consequences such as practice restrictions, loss of scholarships, and post-season limitations. Multiyear rates are based on a four year cohort (Student-Athletes Continue Classroom Success, 2013). According to the Student-Athletes Continue Classroom Success (2013),

In order to compete in the 2013-2014 postseason, teams must achieve a 900 multi-year APR or a 930 average over the most recent two years. The same standard was in place for the 2012-2013 academic year. This standard will increase to a multi-year rate of 930 which predicts a Graduation Success Rate of approximately $50 \%$ or a 940 two year average APR for the 2014-2015 postseason. (para. 10)

The improvements provided by APRs over previous metrics make it likely that APRs will serve as a primary measure of student-athlete success for the foreseeable future. 


\section{Statement of the Problem}

Because of its importance to both students and programs, data produced using the APR formula should be examined on a regular basis to confirm that this metric is capturing the information for which it is intended. This is especially true as NCAA regulations continue to increase each year to support teams that are academically focused as wells as athletically successful. Therefore, the aim of this study was to investigate the accuracy of the APR metric as a predictor of GSR among student-athletes within the Southeastern Conference (SEC). In addition, this study also sought to examine the relationship between GSR and FGR. Data were collected to statistically examine the relationship between APR and GSR. These data were then used to compare GSR to FGR values among sports within major collegiate athletic programs. Such reviews can allow higher education professionals, athletic administration, and the NCAA to better understand the relationships among APR, GSR, and FGR metrics so that these tools can be effectively utilized to guide the academic training of student-athletes.

\section{Research Questions That Guided the Study}

1. What are the data structures of Federal Graduation Rates, Graduation Success Rates, and Academic Progress Rates from Southeastern Conference Institutions?

2. What is the relationship between Federal Graduation Rates and Graduation Success Rates?

3. What is the relationship between Graduation Success Rates and Academic Success Rates?

4. Are modifications needed in the calculation of Academic Progress Rates and, if so, can recommendations be made?

\section{Methods}

\section{Sample Population and Data Source}

This study utilized FGR, GSR, and APR statistics reported by 14 Division I NCAA institutions within the Southeastern Conference (SEC). The institutions were all four-year colleges and universities, both public and private institutions. The 14 academic institutions represented were: University of Alabama, University of Arkansas, Auburn University, University of Florida, University of Georgia, University of Kentucky, Louisiana State University, Mississippi State University, University of Mississippi, University of Missouri, University of South Carolina, University of Tennessee, Texas A\&M University, and Vanderbilt University. The data for this study were collected by the NCAA on an annual basis from 2003-2006. Data reported by the NCAA and Federal Government are public information and accessible for research purposes. The data used were obtained directly from the NCAA by manual searches of the NCAA research database, as well as, through the NCAA Data Sharing Initiative (Paskus, 2013). The NCAA maintains records of APR, GSR, and FGR scores for all universities that accept federal funding. The final data set consisted of 240 scores for APR, GSR, and FGR within each of the 14 universities. The total data set was 720 total scores. Both men's and women's athletic teams were represented in the data as were multiple ethnicity groups. However data were not available for each sport for all years from each university. Some sports had data from all three years (20032004, 2004-2005, and 2005-2006) while others had reports for just one or two of those years. 
Though all sports were not studied over all three years, all data sets used for analyses had all three scores (APR, GSR and FGR) included for the year or years that were studied. Furthermore, to account for intrinsic differences among sports programs (e.g., Football vs Women's Soccer), each sport was evaluated as a whole dataset, independent of institution or location. The specific numbers of scores obtained for each sport are presented below (Table 1).

Table 1. Sport and Data Metrics

\begin{tabular}{lllr}
\hline Sport & Gender & Professional & Number of Scores \\
\hline Baseball & Men & Pro & 37 \\
Basketball & Men & Pro & 7 \\
Basketball & Women & Pro & 10 \\
Bowling & Women & Pro & 1 \\
Football & Men & Pro & 42 \\
Golf & Men & Pro & 3 \\
Golf & Women & Pro & 3 \\
Gymnastics & Women & Non-pro & 9 \\
Lacrosse & Women & Non-pro & 3 \\
Soccer & Men & Pro & 6 \\
Soccer & Women & Non-pro & 33 \\
Softball & Women & Non-pro & 24 \\
Swimming & Men & Non-pro & 20 \\
Swimming & Women & Non-pro & 31 \\
Tennis & Men & Pro & 1 \\
Tennis & Women & Pro & 2 \\
Volleyball & Women & Non-pro & 8 \\
& & & TOTAL
\end{tabular}

Note. Seventeen sports represented in the study and the number of data points (scores) obtained for each of three metrics (APR, GSR, and FGR).

\section{Data Set and Analyses}

A data set containing the 240 individual scores for APR, GSR, and FGR (720 total) was created with additional variables for School (1-14), Sport (1-17), Gender (Men / Women), and Professional (Pro/Non-pro). For the purpose of this study, a professional sport is one that an athlete can compete in and fully support themselves financially based solely on their salary in the sport after their collegiate career. A non-professional sport is one in which an athlete participates and may be paid for doing so, however, they are not self-sufficient based solely on the salary they earn from competition. It is important to note that though some of these sports do have professional leagues, the determination was based on the restrictive condition of whether an athlete could be solely selfsufficient by just participating in their sport outside of sponsorships, TV commercials, and/or additional employment. These data classifications yielded 124 scores for Female sports and 116 for Male sports. Ten sports were considered Professional (112 scores) with seven Non-professional (128 scores).

The full 720 data matrix was used to evaluate the overall data structure. Subdivisions of the data were then analyzed to address specific questions. These data subsets are described in detail along with their analyses in the Results section. Descriptive statistics, $t$ tests, and Pearson ProductMoment Correlations were generated for the full and subdivided data sets. Bonferroni corrections were applied to $p$ values whenever multiple comparisons involving the same data set were calculated. 


\section{Findings}

\section{Descriptive Statistics}

Descriptive statistics were generated for each of the three metrics using the full 720 score dataset (Figure 1). For FGR, the reported scores ranged from 0 to 100 with the mean FGR \pm S.D. estimated to be $66.2 \pm 23.3$. The range of scores for GSR was similar $(25-100)$, but the mean GSR was higher at $83.0 \pm 17.6$. Higher yet were both the range and mean for APR scores (scaled range $=$ $82.7-100$; mean $95.6 \pm 3.4$ ). $T$ tests among the three means produced significant results for all comparisons (Bonferroni adjusted $p<0.017$ in all tests). Further comparisons of the distributions of FGR, GSR, and APR scores are described in Figure 1 below.

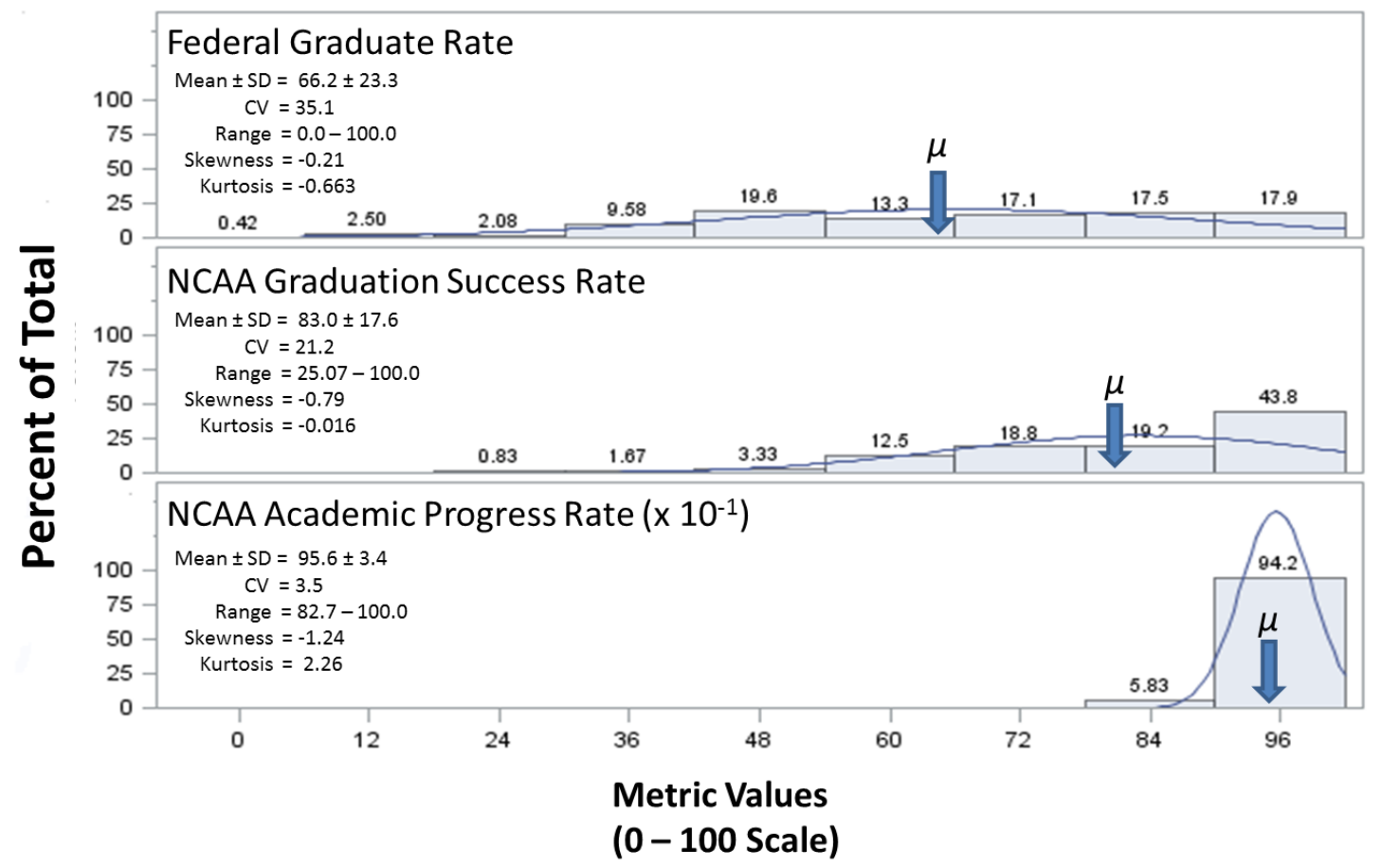

Figure 1. Comparisons of the distributions of FGR, GSR, and APR scores.

Frequency distributions and associated statistics for FGR, GSR, and APR metrics from 14 NCAASEC colleges are presented in Figure 1. Each distribution represents a total of 240 data points. APR values were scaled in Figure 1 to range between $0-100$ to permit direct comparisons. Numbers above each bar graph represent the \% of total values. The coefficient of variation (CV) is displayed using the standard formulation as a ratio of the standard deviation to the mean for each academic progress rate. The higher the $\mathrm{CV}$, the greater the dispersion in the variable. As seen in Figure 1, the dispersion and CV are highest in the FGR.

To more closely examine the patterns within the FGR, GSR, and APR metrics, descriptive statistics were calculated for sports for which 20 or more scores were available. These sports included Men's Baseball, Men's Football, Men's Swimming, Women's Softball, Women's Soccer, and Women's Swimming (Table 2). 
Table 2. GSR, FGR and APR by Sport

\begin{tabular}{lccccccc}
\hline \multicolumn{1}{c}{ Sport } & $\begin{array}{c}\text { Sample } \\
\text { Size }\end{array}$ & $\begin{array}{c}\text { GSR } \\
\text { Mean }\end{array}$ & SD & $\begin{array}{c}\text { FGR } \\
\text { Mean }\end{array}$ & SD & $\begin{array}{c}\text { APR } \\
\text { Mean }\end{array}$ & SD \\
\hline Baseball & 37 & 76.2 & 19.0 & $\mathbf{4 1 . 5}$ & 18.7 & $\mathbf{9 3 4 . 4}$ & 33.2 \\
Football & 42 & $\mathbf{6 9 . 1}$ & 13.3 & 55.0 & 12.9 & 941.6 & 26.8 \\
Swimming (Men) & 20 & 76.7 & 20.4 & 65.4 & 21.5 & 961.3 & 27.1 \\
Softball & 24 & 90.7 & 15.8 & 75.2 & 17.6 & 964.5 & 32.4 \\
Soccer (Women) & 33 & 90.0 & 12.8 & 67.9 & 21.4 & 967.9 & 22.5 \\
Swimming (Women) & 31 & $\mathbf{9 2 . 5}$ & 9.4 & $\mathbf{8 1 . 3}$ & 16.9 & $\mathbf{9 7 6 . 0}$ & 15.0 \\
\hline
\end{tabular}

Note. Descriptive statistics for GSR, FGR, and APR for sports where > 20 scores were available. High and low values for each mean are in bold. GSR and FGR are measured on a scale of 100. APR is measured on a scale of 1000 .

For all three metrics from these sports, scores from Women's sports were consistently higher than Men's with Women's Swimming scores averaging the highest in all three measures (APR, GSR, and FGR). For the GSR metric, the mean for Women's Swimming was $92.5 \pm 9.4$ which was $34 \%$ higher than the lowest mean (Football $69.1 \pm 13.3$ ). Women's Swimming also had the highest mean for FGR at $81.3 \pm 16.9$. This value was almost double the average of the lowest reported FGR (Baseball $41.5 \pm 18.7$ ). And finally for APR, the mean score for Women's Swimming was $976.0 \pm 15.0$, with Baseball again exhibiting the lowest mean at $934.4 \pm 33.2$.

Overall, the greatest differential across sports was observed among FGR estimates (range 41.5 81.3). GSR values showed substantial consistency within genders, but substantial variation between (69.1 - 76.7 for male sports and 90.0 - 92.5 for female). In contrast, the APR estimates for these six sports exhibited very little spread in mean scores (934.4 - 976.0).

\section{Analysis on FGR, GSR and APR from SEC Schools.}

For the full 240 point data set examined in this study, the observed distributions for FGR, GSR, and APR reflected substantial differences (Figure 1). As evidenced by the standard deviation $(S D)$, $\mathrm{CV}$ (coefficient of variation), range, and skewness estimates, FGR exhibited the widest distribution in reported scores. This finding was in stark contrast to the extreme distribution observed for APR scores where were highly compressed in the range between $827-1000$. This compression is obvious in $S D, \mathrm{CV}$, and kurtosis measures calculated from the APR scores. Small $S D$ (3.4) and CV (3.5) values reflect the highly leptokurtic nature of the APR distribution (kurtosis $=2.28$ ). Falling in the middle were the GSR scores, with the mean GSR (83.0) being higher than the FGR estimate but lower than APR (scaled to 100). Of the three distributions, GSR had the lowest kurtosis estimate $(-0.016)$ indicating that these values were the most evenly spread of the three metrics, despite the somewhat higher level of overall skewness (-0.079).

For the full 240 score data set, at 0.679 the correlation between FGR and GSR was both positive and significantly greater than zero $(p<0.001)$. The coefficient of determination $\left(\mathrm{CD}=r^{2}\right)$ was 0.46 indicating that $46 \%$ of the variation in FGR (or GSR) could be explained by the other metric. These results indicate that for the years examined in this study the GSR scores reported by the 14 SEC Schools, while higher overall, were positively related to the federal scores from the same institution (Table 3). 
Table 3. Correlations for FSR/GSR and APR/GSR

\begin{tabular}{lccl}
\hline Sport & Sample Size & $\boldsymbol{r}^{\mathbf{F}-\mathbf{G}}$ & \multicolumn{1}{c}{$\boldsymbol{r}^{\mathbf{A}-\mathbf{G}}$} \\
\hline Baseball & 37 & 0.398 & 0.232 \\
Football & 42 & $0.566^{*}$ & 0.162 \\
Swimming(Men) & 20 & $0.882^{*}$ & $0.733^{*}$ \\
Soccer (Women) & 33 & $0.684^{*}$ & 0.448 \\
Softball & 24 & $0.662^{*}$ & $0.608^{*}$ \\
Swimming (Women) & 31 & $0.559^{*}$ & 0.021 \\
\hline
\end{tabular}

Note. Pearson correlation statistics $(r)$ between FGR/GSR $(r \mathrm{~F}-\mathrm{G})$ and APR/GSR $(r A-G)$ metrics. Asterisks $(*)$ indicate Bonferroni adjusted significance value $p<0.008$.

Correlation estimates between FGR and GSR for the set of individual sports having > 20 scores are reported in Table 3. With the exception of Men's Baseball, all of the correlations between FGR and GSR scores were found to be positively related and significantly different from zero (Bonferonni adjusted $p<0.083$ ). Of the six sports, Men's Swimming exhibited the strongest positive correlation with an estimated $r$ of $0.882\left(r^{2}=0.78\right)$. In addition, comparisons of FGR to GSR values for Women's Soccer and Softball yielded moderate to strong positive correlations. Lastly, all of the remaining sports, Baseball, Football, and Women's Swimming had slightly lower, but still moderate correlation coefficients.

Correlation analyses again indicated the presence of significant positive relationships when APR scores were compared to FGR and GSR values. The observed correlations were, however, substantially lower that between FGR and GSR directly. Between APR and FGR the correlation was estimated to be $0.433\left(r^{2}=0.22\right)$. For the overall data set comparison between APR and GSR, the correlation estimate was similar at $0.485\left(r^{2}=0.24\right)$.

Having determined that the overall APR relationships to both FGR and GSR were positive and significant, we next focused on determining the strength of the association between APR and GSR for individual sports. Using the same six sports as before, correlation analyses produced an interesting set of outcomes (Table 3). In contrast to the individual FGR/GSR comparisons, only two APR/GSR correlations were found to be significant. Men's Swimming $(r=0.773)$ and Softball $(r=0.608)$ were the two significant estimates $(p<0.008)$, indicating that APR scores reported for these sports tracked GSR values moderately well. Conversely, $r$ and $p$ values for Baseball, Football, Women's Soccer, and Women's Swimming were substantially lower and nonsignificantly different from zero. Of special note was the near complete lack of evidence for any relationship between APR scores from Women's Swimming and their reported GSR metrics. Low coefficients for Baseball and Football also suggest that little correlation may exist between the two metrics for these sports.

\section{Professional vs. Nonprofessional}

Classification dichotomies of additional interest in athletics are those sports defined earlier as professional and nonprofessional. To compare and contrast the relationships among FGR, GSR, and APR for these sports, Pearson's correlation coefficients were again calculated (Table 4). The data were composed for 112 professional sport samples and 128 nonprofessional sport samples. Pearson's $r$ between FGR and GSR for nonprofessional sports was moderate with a value of 0.693 $\left(r^{2}=0.48\right)$ with the value for professional sports being similar but lower at $0.550\left(r^{2}=0.30\right)$. 
Table 4. Correlation Statistics for FGR/GSR and APR/GSR

\begin{tabular}{lccc}
\hline Group & Sample Size & $\boldsymbol{r}^{\mathbf{F}-\mathbf{G}}$ & $\boldsymbol{r}^{\mathbf{A}-\mathbf{G}}$ \\
\hline Professional & 112 & 0.550 & 0.336 \\
Non-Professional & 128 & 0.693 & 0.469 \\
Men's Sports & 116 & 0.517 & 0.314 \\
Women's Sports & 124 & 0.600 & 0.366 \\
\hline
\end{tabular}

Note. Pearson correlation statistics $(r)$ between FGR/GSR $\left(r^{\mathrm{F}-\mathrm{G}}\right)$ and

APR/GSR $\left(r^{\mathrm{A}-\mathrm{G}}\right)$ metrics for groupings described in text. All correlation coefficients were significantly $>$ zero $(p<0.001)$.

As seen in previous comparisons, the correlations between APR and GSR were lower than for FGR with GDR, but the overall pattern was consistent. Professional sports again exhibited the lowest inter-metric correlation at $0.336\left(r^{2}=0.11\right)$ while the relationship for nonprofessional sports based data was again in the moderate range at $0.469\left(r^{2}=0.22\right)$.

\section{Differences Between Male and Female Sports}

Information on student success rates partitioned by gender is essential data for evaluating academic enhancement programs for athletes. The FGR, GSR, and APR data available in this study were divided between male and female sports to examine this topic. Subdivision of the dataset yielded 116 scores for sports comprised of male participants and 124 scores for female participant sports (Table 1). Results of the correlation analyses indicated that $r$ valves between genders were roughly equivalent for both FGR/GSR and APR/GSR comparisons. However, once again, the observed $r$ values differed substantially between metric pairs (Table 4). For the FGR/GSR comparisons, the correlation value for female sports was $0.600\left(r^{2}=0.36\right)$ with the estimate for male sports only slightly lower at $0.517\left(r^{2}=0.27\right)$. Comparisons between the APR and GSR metrics showed much less association (Table 4; male sports $r^{2}=0.10$; female sports $r^{2}=0.13$ ).

\section{Discussion}

The ultimate goal of any academic institution is to graduate well-educated, well-prepared students. Meeting this goal for student-athletes presents unique challenges to academic programs. Tinto (1997) formulated a theory explaining the process of what motivates individuals to leave colleges and universities before the completion of a degree (Cabrera, Castaneda, Nora, \& Hengstler, 1992). As Tinto (1997) noted, "One thing we know about persistence is that involvement matters. The more academically and socially involved individuals are; that is, the more they interact with other students and faculty, the more likely they are to persist" (p. 168). The greater a student's involvement in college life, the more likely they are to develop knowledge and academic skills to be successful and persist throughout college to graduation.

With all students, to maximize retention, it is necessary to get students involved, especially early in their college careers. Retention is a particular issue with student-athletes because they face extra pressures that traditional students rarely encounter (Tinto, 1999). However, student-athletes are students first, and in order to succeed academically and socially, there are certain factors that must be present within the university to aid in succeeding and retaining them. There are six conditions within an institution's control that aid in the retention and support of student success. These conditions are commitment, expectations, support, feedback, involvement, and learning (Tinto, 1999). To focus attention on this issue, a series of academic progress standards have been put into 
place by the NCAA to ensure student-athletes are earning credits toward the ultimate goal of graduating with a four-year degree (Christy, Seifried, \& Pastroe, 2008).

This study was designed to evaluate the relationship between three metrics used by the NCAA as part of the monitoring and compliance program for academic achievement by student-athletics. Of key interest was the development of an increased understanding of the relationship between the widely applied measure of academic progress (APR) and graduation rates (FGR and GSR). The central question driving this research was, "Does the information captured by APRs accurately reflect progress toward the ultimate academic goal, namely graduation?" An ancillary question was whether the Graduate Success Rate (GSR) metric of the NCAA accurately tracks the more global Federal Graduate Rate (FGR). These questions are important because the consequences of either succeeding or failing to reach NCAA standards for these metrics can be very important for both athletic programs and their home institutions.

The rewards for successful athletics can involve such diverse dynamics as alumni giving (Koo \& Dittmore, 2014), general student body graduation rates (Tucker, 2004), external institutional prestige (Clopton \& Finch 2012), and the impact of sports tourism on community economics (Dixon, Henry, \& Martinez, 2013). Conversely, failure to meet minimum NCAA standards for the GSR or APR can severely impact any athletic program. Direct effects resulting from loss of scholarships, reductions in practice times, and bans on post-season games combined with the indirect effects of negative publicity can hinder a program for many years. Not surprisingly, institutions and their athletic programs invest substantial resources and personnel to help avoid such sanctions. Research aimed at better understanding the metrics from which the NCAA makes such decisions is obviously of critical importance.

GSR and FGR. The GSR was developed by the NCAA as an alternative to the FGR in response to concerns that the FGR failed to account for special conditions that apply to student-athletes, specifically the transfer of athletes who are in good academic standing. According to LaForge and Hodge (2011),

The major difference between GSR and FGR is the definition of the cohort group. With FGR, the cohort group is defined and "locked in" at the beginning of the school year, and the graduation of those students is tracked six years later. With GSR, the cohort group is modified by adding transfers and midyear enrollees and subtracting early departures in good academic standing. (p. 222)

The NCAA has been tracking GSR in comparison to FGR since 1998. GSR averages for studentathletes consistently outpace the FGR collected for student-athletes and the general student population. The NCAA's method of computing graduation success for student-athletes clearly yields a higher graduation rate than the FGR. Results from our analyses of data from the 14 SEC programs support this observation. The average GSR score (83.0) was $25.4 \%$ greater than the average FGR (66.2) for the 14 institutions. In addition, estimates for both standard deviations and kurtosis were substantially smaller for the distribution of GSR scores reflecting a tighter range of reported values in comparison to the FGR metric. Moreover, the observed $r^{2}$ indicated that only approximately $46 \%$ of the variation in one metric could be explained by variation in the other. The NCAA argues that these differences exist because GSR is a more accurate metric for athletes (Grad Rates Hit High Marks, 2010). According to the NCAA (2010), 
By counting incoming transfer students and midyear enrollees, the GSR increases the total number of student-athletes tracked for graduation by more than $36 \%$. The NCAA also calculates the FGR for student-athletes. It is the only rate by which to compare studentathletes to the general student body. (p. 1)

Noticeably for GSR, institutions are not penalized for outgoing transfer students who leave an institution in good academic standing and are given additional points toward the overall rate for students that transfer into an institution and graduate (Grad Rates Hit High Marks, 2010). These two differences between FGR and GSR greatly affect the overall scores.

The GSR is considered a useful measure to assess the academic performance of teams within an institution. A low GSR often indicates that the academic performance within a particular team is poor, because GSR does not take into account when a student-athlete leaves in good academic standing. On the other hand, FSR may or may not indicate low academic performance because it penalizes an institution for a student who leaves early whether or not they are academically eligible. Therefore, campus comparisons of GSR between sports is valid and useful because it reflects the same academic rigors among teams, and it removes the effects of differing professional opportunities from sport to sport (LaForge \& Hodge, 2011). The results from our study were consistent with this argument. A 34\% differential was observed between average scores when the dataset was divided among teams (Table 2). However, review of results from the correlation analyses for individual sports does suggest caution is needed. Comparisons of the pattern of mean values from Table 2 with the pattern of relationships in Table 3 does not indicate any direct association between the GSR and FGR data from these sports. While the GSR metric was specially designed to capture information not associated with FGR, some form of a general association might be expected given the positive, significant overall Pearson correlation coefficient (0.679). Variation in the pattern of the two metrics suggests that important underlying factors may exist for multiple sports, as have been previously reported in other student-athlete research studies, including men's Basketball (Matheson, 2007) and Football (Sack, Park, \& Thiel, 2011).

Differences between FGR and GSR scores are well documented and multiple explanations have been proposed. The obvious observation is that the GSR was in fact designed to be different from the FGR as its calculation involves additional variables specific to athletics. These differences clearly account for some elevation in the reported GSRs over FGRs. However other, less positive, factors have been suggested. As with any performance measure that carries significant consequences, gaming can be expected. One example would be the potential increase in a program's GRS score when a coach credits a walk-on student-athlete with a scholarship they were not receiving prior to their entrance into an academic institution. These student-athletes are then moved into the GSR countable cohort, where previously they were not counted because they did not receive athletic aid (LaForge \& Hodge, 2011). This form of gaming has the potential to happen often because of the immediate GSR gain derived from allocating a student-athlete that has a great academic record a minimal amount of athletic funds. Another common tactic involves clustering of athletes into a few select majors that historically produce higher than average graduate success (Fountain and Finley, 2011). Whether clustering is a positive or negative approach is highly debated. Programs such as Adult Education majors that are designed to provide athletes with leadership, group management, and/or business skills can be highly valuable. Conversely, clustering into programs that provide little or no marketable skill set development for the sole purpose of increasing graduation probabilities is obviously counter-productive. 


\section{APR-An Effective Metric?}

While intended to be an informative method for fairly assessing academic performance within athletic programs, the APR has been highly criticized since its inception (Christy et al., 2008). Unfortunately, the results of our study will likely add additional concerns. The highly compressed distribution of reported APR scores (Figure 1) combined with only a marginal level of correlation with the NCAA's own graduation success measure (GSR) are not characteristics of an effective metric. Indeed such conditions would limit the value of any metric that was used to measure success. The first issue to consider is the marginal amount of correlation between APR scores and GSR. The NCAA has set an APR value of 925 (recently raised to 930) as representing a graduation success rate of $50 \%$. While it is unclear precisely how the NCAA derived this percentage, it is obvious from the marginal correlation estimate (0.485) and minimal coefficient of determination (0.24) obtained in this study that a high degree of accuracy in this association is unlikely for the 14 SEC Schools examined. We interpret these results as indicating that the APR metric exhibits limited predictive power relative to forecasting advancement to the ultimate desired outcome, namely graduation.

The highly compressed nature of the APR distribution (range of scores $=827-1000$ ) is of additional concern. Given the below average FGR rates for student-athletes, it seems highly unlikely that APR scores, that measure short-term advancement toward completion, should average a scaled value near 96\% (Figure 1). Based on our analysis of the data from the 14 schools, this result appears to be a real world example of the Lake Woebegone Effect. This idea is named for the mythical hometown of the satirist Garrison Keillor, "[where] all the children are above average" (Keillor, n.d.). In psychology, this concept relates to the belief of individuals that they are personally superior (illusory superiority). Here the data suggest that forces may be working to make being above average for achievement not a belief, but a reality within athletic programs.

There are likely to be multiple interrelated causes for the APR data pattern in this study. The algorithm and variables used to calculate the metric clearly push the values toward the 1000 maximum, thus compressing the distribution. It is also likely that adjustments allowed by the NCAA are confounding this issue. Adjustments can be made to APR when institutions feel that a loss of a point is not justified. In certain situations, an institution's athletic administration can appeal to the NCAA to adjust their rate. This exception is one of the criticisms voiced against the use of APRs. According to Le Crom, Warren, Clark, Maroll, and Gerber (2009),

After its enactment, changes have already been made to the APR measure. The first of these changes came in the form of forgiving the APR retention point for a student-athlete who leaves school to play sports professionally or for any other reason outside of the control of the student-athlete. (p. 16)

Other approaches to maximize APRs are also available to athlete programs. For example, APRs are only calculated for student-athletes who receive athletic financial aid. This factor can influence the way in which athletic money is distributed to either increase or decrease the population size to produce a positive APR (Le Crom et al., 2009). Clustering is another approach that critics suggest is used to elevate APR scores. These methods of "correction" coupled with the specialized academic assistance routinely provided to student-athletes appear to have a significant influence on the range of APR scores. 
Journal of Global Education and Research, Vol. 2, Iss. 1 [2018], Art. 1, pp. 1- 16

Our central concern about the APR relates to general problems that arise when decisions are based on any highly skewed distribution. It is frequently the case that very small changes in input can result in very large movements within bounded distributions. In terms of our results, we conclude that seemingly simple decisions, such as to provide scholarships to a few, select athletes could radically alter a team's average APR. Equally concerning is a related problem that small movements in an APR score might easily move a program from the top 50\% to the bottom or vice versa. This type of issue is widely observed on teaching evaluations were average scores are often highly clustered, for example around 4.0 out of a 1-5 scale. Under these conditions, one question might move an instructor's combined score from 4.1 to 3.9 and in doing so move them from the top $30 \%$ to the bottom $30 \%$.

Clearly, metrics that suffer from such limitations as discussed above are problematic if used as the basis for critical decision making. Given the serious consequences associated with failure to reach NCAA mandated standards for APR scores, it is essential that this metric be both a precise and accurate measure of advancement toward graduation. With the issues highlighted by our examination and the valid criticisms commonly cited, our conclusion is that revision of the NCAA's approach to calculating the APR is both warranted and necessary.

\section{Comparisons of Metrics from Male and Female Sports}

Our analysis of data from the 14 SEC Schools divided by gender indicated that substantial differences were apparently. As Denhart, Villwock and Vedder noted (2009), "there is a great disparity in GSR rates by gender and sport" (p. 12). Gender has also been identified in multiple studies as a key variable impacting APR scores (Le Crom et al., 2009; Johnson, Wessel, \& Pierce, 2012). This is illustrated in the report by Denhart et al. (2009) for cohorts 1997-2000 and 19982001. Females in the 1997-2000 cohort graduated at a rate $17 \%$ higher than their male counterparts; and in the 1998-2001 cohort, females graduated at a rate 16\% higher than their male counterparts. As further noted by Denhart et al. (2009),

Male sports dominate athletic budgets. However, female athletes graduated at a $16 \%$ higher rate than male athletes in the 1998-2001 study years. The proportion of allocated funds to male sports programs verses female sports programs correlates negatively with graduation rates. (p. 12)

An examination into specific sports at the University of Wisconsin-Madison showed an even greater disparity among male and female athletes. The male sports that generated the most revenue, which are Basketball and Football, had some of the lower GSR scores compared to that of their female counterparts and non-revenue generating male sports. In comparison, female sports, which did not generate considerable revenue, had much higher GSR than the male sports. The results reported here suggest that this trend may be also occurring within SEC programs.

\section{Conclusions and Future Research}

Our analysis of FGR, GSR, and APR metrics from 14 SEC athletic programs identified some unusual and potentially troublesome features. Two key problematic characteristics were associated with the APR metric. With $r^{2}$ estimates between APR and GSR averaging less than 0.13, there appeared to no significant predictive relationships. Furthermore, the highly skewed nature of the 
observed APR distribution leads us to caution that the metric has both poor discrimination potential and could be highly susceptible to manipulation. In conjunction with existing criticisms, our results bring into question the value of the existing APR metric formulation for its intended purpose. We conclude that additional consideration of this metric is warranted.

This study was conducted in the beginning stages of three years of data that overlapped between APR, GSR, and FGR. Therefore, future studies will benefit from a larger sample size and more years of complete data sets. In addition to more years of complete data, the sample size can be increased by enlarging the region, conference, and divisions that are studied. As more data are reported and made public by the NCAA and athletic institutions, this will improve research and use of the metrics. By increasing the sample size and expanding the scope of the data, it will also allow the researcher to study more divisions, conference, universities, and sports. The NCAA may potentially review the APR metric and making adjustments to broaden the distribution.

In addition to increasing the sample size that is studied, it would also be beneficial to see how metrics have changed throughout the increased scrutiny and popularity of the data. How each of the scores have also been calculated and used throughout the years of the data that overlap would also increase the validity and reliability of the results. Results of the recommended study will provide a better understanding of each of the above metrics as they apply to a larger spectrum of universities, student-athletes, professional vs. nonprofessional students, male vs. female, and academic standards within each of the three divisions within the NCAA.

\section{References}

Academic Progress Rates. (n.d.). Retrieved from http://www.ncaa.org/about/resources/research/academic-progressrate-apr

Cabrera, A. F., Castaneda, M. B., Nora, A., \& Hengstler, D. (1992). The convergence between two theories of college persistence. The Journal of Higher Education, 63(2), 143-164.

Chen, X., Bersudskaya, V., \& Cubarrubi, A. (2011). Statistical methods for protecting personally identifiable information in the disclosure of graduation rates of first-time, full-time degree or certificate-seeking undergraduate students by 2-year degree-granting institutions of higher education. (Technical Brief NCES 2012-151). Washington, DC: National Center for Education Research.

Christy, K., Seifried, C., \& Pastore, D. L. (2008). Intercollegiate athletics: A preliminary study examining the opinions on the impact of the academic performance rate (APR). Journal of Issues in Intercollegiate Athletics, 1, 1-10.

Clopton, A. W., \& Finch, B. L. (2012). In search of the winning image: Assessing the connection between athletics success on perceptions of external prestige. Journal of Issues in Intercollegiate Athletics, 5, 79-95.

Comeaux, E. (2011). A study of attitudes toward college student-athletes: Implications for faculty-athletics engagement. Journal of Negro Education, 80(4), 521-532.

Denhart, M., Villwok, R., \& Vedder, R. (2010). The academics-athletics trade-off: Universities and intercollegiate athletics (pp. 1-52). Washington, DC: Center for College Affordability and Productivity.

Division I Academic Progress Rate. (2011.). Retrieved from https://web1.ncaa.org/app_data/apr2010/440_2010_apr.pdf

Dixon, A. W., Henry, M., \& Martinez, J. M. (2013). Assessing the economic impact of sport tourists' expenditures related to a university's baseball season attendance. Journal of Issues in Intercollegiate Athletics, 6, 96-113.

Ferris, E., Finster, M., \& McDonald, D. (2004). Academic fit of student-athletes: An analysis of NCAA Division I-A graduation rates. Research in Higher Education, 45(6), 555-575.

Fountain, J. J., \& Finley, P. S. (2011). Academic clustering: A longitudinal analysis of a Division I football program. Journal of Issues in Intercollegiate Athletics, 4, 24-41.

Grad rates hit high marks. (2010). Retrieved from http://www.ncaa.org/wps/wcm/connect/public/NCAA/Resources/Latest\%20News/2010\%20news\%20storie s/October/Grad\%20rates\%20hit\%20high\%20marks 
Graduation rates. (n.d.). Retrieved from http://www.ncaa.org/about/resources/research/graduation-rates

Horn, L. (2010). Tracking students to 200 percent of normal time: Effect on institutional graduation rates. (Issue Brief NCES 2011-221). Washington, DC: National Center for Education Statistics.

Johnson, J. E., Wessel, R. D., \& Pierce, D. (2012). The influence of selected variables on NCAA academic progress rate. Journal of Issues in Intercollegiate Athletics, 5, 149-171.

Keillor, G. (n.d.). National Geographic: In search of Lake Wobegon. Retrieved from: http://www.garrisonkeillor.com/national-geographic-in-search-of-lake-wobegon/

Kirkpatrick, N., Hawkins, B., Hill, J., \& Maxcy, J. (2014). The impact of the academic progress rate (APR) on low resource or non-BCS institutions as it relates to football and/or men's basketball programs. Journal of Issues in Intercollegiate Athletics, 7, 263-284.

Koo, G., \& Dittmore, S. W. (2014). Effects of intercollegiate athletics on private giving in higher education. Journal of Issues in Intercollegiate Athletics, 7, 1-16.

LaForge, L., \& Hodge, J. (2011). NCAA academic performance metrics: Implications for institutional policy and practice. The Journal of Higher Education, 82(2), 217-235.

Le Crom, C. L., Warren, B. J., Clark, H. T., Marolla, J., \& Gerber, P. (2009). Factors contributing to student-athlete retention. Journal of Issues in Intercollegiate Athletics, 14(24), 14-24.

Matheson, V. A. (2007). Research note: Athletic graduation rates and Simpson's Paradox. Economics of Education Review, 26, 516-520.

NCAA Division I Manual, 2012 - 2013. Retrieved from: http://www.ncaapublications.com/p-4270-division-i-manual-published-april-2012-pdf-and-epubversions.aspx

Paskus, T. (2013) NCAA Division I Academic Progress Rate. (ICPSR26801-v3) Ann Arbor, MI: Inter-university Consortium for Political and Social Research [distributor]. doi:10.3886/ICPSR26801.v3

Petr, T. A., \& Paskus, T. S. (2009). The collection and use of academic outcomes data by the NCAA. New Directions for Institutional Research, 144, 77-92.

Sack, A. L., Park, E. A., \& Thiel, R. (2011). Historical context. Journal of Issues in Intercollegiate Athletics, 4, 5573.

Sander, L. (2009). Athletes' graduation rates hit another high, NCAA says. Retrieved from: https://www.chronicle.com/article/Athletes-Graduation-Rates-Hit/49202

Southall, R. M. (2012). Taking the measure of graduation rates in big-time college sports. Phi Kappa Phi Forum, 92(3), 18-20.

Student-athletes continue academic success. (2013). Retrieved from http://www.ncaa.org/about/resources/media-center/news/student-athletes-continue-classroom-success

Tinto, V. (1997). Classrooms as communities: Taking research on student persistence seriously. The Review of Higher Education, 21(2), 167-177.

Tinto, V. (1999). Taking student success seriously: Rethinking the first year of college. NACADA Journal, 19(2), 59

Tucker, I. B. (2004). A reexamination of the effect of big-time football and basketball success on graduation rates and alumni giving rates. Economics of Education Review, 23, 655-661.

Waller, J. M. (2003). A necessary evil: Proposition 16 and its impact on academics and athletics in the NCAA. DePaul Journal of Sports Law \& Contemporary Problems, 1(2), 189-206. 